\title{
Profiling household double and triple burden of malnutrition in sub-Saharan Africa: prevalence and influencing household factors
}

\author{
Aaron K Christian and Fidelia AA Dake* \\ Regional Institute for Population Studies, University of Ghana, LG 96 Legon, Accra, Ghana
}

Submitted 28 July 2020: Final revision received 29 March 2021: Accepted 19 April 2021: First published online 26 April 2021

\begin{abstract}
Objective: Undernutrition and anaemia (the commonest micronutrient deficiency), continue to remain prevalent and persistent in sub-Saharan Africa (SSA) alongside a rising prevalence of overweight and obesity. However, there has been little research on the co-existence of all three conditions in the same household in recent years. The current study examines the co-existence and correlates of the different conditions of household burden of malnutrition in the same household across SSA. Setting: The study involved twenty-three countries across SSA who conducted Demographic and Health Surveys between 2008 and 2017.

Participants: The analytical sample includes 145020 households with valid data on the nutritional status of women and children pairs (i.e. women of reproductive age; $15-49$ years and children under 5 years).

Design: Logistic regression analyses were used to determine household correlates of household burden of malnutrition.

Results: Anaemia was the most common form of household burden of malnutrition, affecting about seven out of ten households. Double and triple burden of malnutrition, though less common, was also found to be present in 8 and $5 \%$ of the households, respectively. The age of the household head, location of the household, access to improved toilet facilities and household wealth status were found to be associated with various conditions of household burden of malnutrition. Conclusions: The findings of the current study reveal that both double and triple burden of malnutrition is of public health concern in SSA, thus nutrition and health interventions in SSA must not be skewed towards addressing undernutrition only but also address overweight/obesity and anaemia.
\end{abstract}

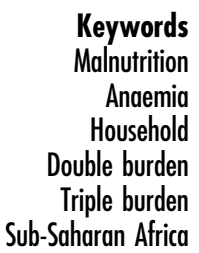

The 2020 Lancet series on the 'dynamics of the double burden of malnutrition and the changing nutrition reality' suggests that the global health community has been slow in acknowledging and responding to the high prevalence of the double burden of malnutrition, particularly in low and middle countries ${ }^{(1)}$. Historically, malnutrition has been linked with different population sub-groups, and the divide has mostly been by socio-economic status; undernutrition was linked to resource poor populations, while overweight and obesity were associated with the affluent ${ }^{(2)}$. This predisposition often led to a functional divide when addressing malnutrition challenges. However, over the past two decades, there have been indications that undernutrition and overweight/obesity are increasingly co-occurring and becoming a public health $\operatorname{problem}^{(3)}$ with no socio-demographic and or wealth/income groupings spared $^{(4)}$. Additionally, although globally, no regional block has been exempted from the rising prevalence of overweight/obesity which has translated into the current obesity pandemic $^{(5)}$, sub-Saharan Africa (SSA) has been observed to be experiencing a rapid rise in overweight/obesity, and the region also continues to be the only region where undernutrition is on the rise in almost all its sub-regions ${ }^{(6)}$. The rise in the burden of overweight and obesity in low-resource countries was highlighted by Barry Popkin in his seminal work on the nutrition transition, in which he projected that the rate of dietary changes such as consumption of energy-dense foods and increasing decline in physical activity among the poor could result in an upsurge of overweight and obesity in developing countries ${ }^{(7,8)}$.

*Corresponding author: Email faadake@st.ug.edu.gh

(c) The Author(s), 2021. Published by Cambridge University Press on behalf of The Nutrition Society. This is an Open Access article, distributed under the terms of the Creative Commons Attribution licence (http://creativecommons.org/licenses/by/4.0/), which permits unrestricted re-use, distribution, and reproduction in any medium, provided the original work is properly cited. 
These changes in lifestyle habits could also be viewed as socially constructed choices that are modulated or influenced by various commercial interests ${ }^{(, 10)}$. Furthermore, the commercial determinants of health, defined as 'strategies and approaches used by the private sector to promote products and choices that are detrimental to health', are now viewed as a critical element in understanding ways of addressing the current levels of malnutrition ${ }^{(11)}$. Additionally, the increasing penetration and intense advertising of sugar-sweetened beverages by both international and local food companies have a significant influence on the intake of sugars and thus contribute to overweight and obesity. This trend has edged some researchers to advocate for increased attention to be given to both the commercial and social determinants of health ${ }^{(11,12)}$, especially as it relates to malnutrition, particularly overweight and obesity.

In addition to the aforementioned challenges, the SSA region is also the hardest hit with regard to the consequence of climate change. The increasing temperatures and extreme rainfall that characterise climate change are altering suitable conditions for farming. Additionally, given its impact on agricultural systems, climate change significantly slows down progress towards improving the food security of households in $\operatorname{SSA}^{(13)}$. The work of the Intergovernmental Panel on Climate Change provides adequate evidence about the link between climate change, food insecurity and undernutrition, particularly among vulnerable populations in sub-Saharan Africa, due to crop failures, reduced food production and increased foodborne diseases. The interaction between climate change and food security is complex and its impact on malnutrition is multifaceted. On the one hand, there is evidence that whereas severe food insecurity could lower obesity, on the other hand, mild to moderate food insecurity has been shown to be associated with obesity ${ }^{(14)}$. The dynamics of how this paradox impacts household burden of malnutrition needs to be researched.

Increasingly, undernutrition and overweight/obesity are being observed to occur in the same community, in the same household and among different members of the same household ${ }^{(3,15)}$. Malnutrition at the household level is often observed among children and women, but this does not mean men are not affected ${ }^{(16,17)}$. The pattern of malnutrition among children and women in SSA is changing from the previously observed undernutrition among women and children to undernutrition among children and overweight/ obesity among women and even more recently to overweight/obesity among both women and children ${ }^{(18)}$. A more nuanced examination shows the existence of even more permutations of undernutrition and overweight/obesity among women and children in the same household.

Aside undernutrition and overweight/obesity, other nutritional disorders with equally grave public health implications include micronutrient deficiencies with irondeficiency anaemia being the most widespread ${ }^{(19)}$.
Currently, the prevalence of iron-deficiency anaemia is the highest among all nutritional deficiencies around the world $^{(20)}$ and in developing countries ${ }^{(21)}$. Unfortunately, over the past decade, SSA has achieved the lowest progress with respect to reducing the prevalence of irondeficiency ${ }^{(22,23)}$. Consequently, SSA is particularly vulnerable to the burden of all forms of malnutrition; undernutrition, overweight/obesity and micronutrient deficiency and even worse, their simultaneous co-existence. And regardless of the condition of malnutrition, the consequences are largely negative. Childhood undernutrition for instance is associated with increased risk of mortality and poor cognitive development $^{(24)}$, while overweight/obesity is associated with increased incidence of chronic non-communicable diseases ${ }^{(25)}$. Maternal overweight/obesity on the other hand is linked with various adverse maternal as well as fetal outcomes $^{(26)}$. Consequently, the co-existence of undernutrition, overweight/obesity and anaemia exacerbate the burden of ill-health and retards development among household members.

Household burden of malnutrition can be classified by the collective burden among individual members of the household. Double/dual burden of malnutrition (DBM) is considered as the co-existence of maternal overweight and obesity along with child undernutrition within the same household ${ }^{(27,28)}$, while triple burden of malnutrition (TBM) refers to the co-existence of overweight/obesity, undernutrition and micronutrient deficiency ${ }^{(29,30)}$ in the same household. It is also worth stating that, there could be the co-existence of overweight/obesity and micronutrient deficiency in the same individual and this could occur in either a child or the mother (adult woman). A child can also simultaneously be overweight/obese and stunted. This is also another form of individual-level double burden of malnutrition ${ }^{(31)}$.

Double and triple burden malnutrition households are becoming more common and rising rapidly in SSA partly due to the ongoing rapidly evolving nutrition transition ${ }^{(3,32)}$. Additionally, whereas structural and institutional changes such as unregulated marketing of cheap processed foods and sugar-sweetened beverages and the lack of physical activity and physical activity spaces are identified as critical factors driving overweight/obesity ${ }^{(33,34)}$, the region's continued high levels of food insecurity, HIV prevalence and per capita income have been identified to be associated with undernutrition $^{(35)}$. Furthermore, although the double and triple burden of malnutrition is often reported as a regional or global phenomenon, its expressions and impacts are experienced at the micro-level in households. Thus, exploring correlates of malnutrition, particularly the double and triple burden of malnutrition at the household level, is critical for both public health programmers and policy makers to guide the development and implementation of appropriate policy interventions.

Addressing the double and triple burden of malnutrition in SSA will require understanding the intricacies and 
characteristics of households that have been affected. To our knowledge, overweight/obesity, undernutrition and anaemia in woman-child pairs within the same household have not yet been explored using nationally representative data across SSA. But considering that SSA already has weak health infrastructure, the emergence of this nutritional paradox compromises the regions development even further. Furthermore, if target $2 \cdot 2$ of the Sustainable Development Goals ${ }^{(36)}$ which aims at reducing all forms of malnutrition is to be achieved, the household drivers of the burden of malnutrition need to be effectively understood. Considering the above-mentioned context, we use nationally representative data across SSA, to explore correlates of the different classifications of household malnutrition, i.e. undernutrition, overweight/obesity, anaemia (as an indicator of micronutrient deficiency) as well as their co-existence in the same household. Such analysis will contribute significantly to effective ways of addressing the co-existence of undernutrition, overweight/obesity and anaemia in households in SSA.

\section{Materials and methods}

\section{Data sources and procedures}

The current study used data from the most recent Demographic and Health Survey (DHS) conducted across SSA where data were available. The DHS are standard nationally representative cross-sectional household-based surveys that are conducted approximately every 5 years. Data from the DHS provide indicators on population and health for multi-country comparison. The DHS programme started in the 1980s and has contributed to advancing global knowledge on health and population trends in low- and middle-income countries. All DHS are conducted using a standardised survey design and data collection procedures across participating countries. Typically, the DHS uses a stratified cluster sampling technique to select census enumeration areas based on probability proportional to the size of the enumeration area. This is then followed by a random selection of households within selected enumeration areas. Data collection for the survey is done through face-to-face interviews using questionnaires which are administered to household heads and selected household individuals including women in the reproductive age (15-49 years) who consent to be interviewed. For the purposes of the current study, the following inclusion criteria; (i) only subSaharan African countries, (ii) most recent survey conducted between 2008 and 2017 and (iii) the survey included indicators of children's nutritional status (i.e. stunting, wasting and $\mathrm{Hb}$ concentration) and women's nutritional status (i.e. BMI and $\mathrm{Hb}$ level) were applied in extracting data for the analysis. Based on these criteria, a total sample of 145020 households with women-child pairs from twentythree countries was realised (Table 1). The data for the current study were extracted from IPUMS (Integrated Public Use Microdata Series) DHS ${ }^{(37)}$. IPUMS uses a data
Table 1 Distribution of study sample by country, survey year and final sample size for analysis

\begin{tabular}{lrr}
\hline Country & Year & Sample size \\
\hline Burkina Faso & 2010 & 6649 \\
Burundi & 2016 & 5505 \\
Cameroon & 2011 & 4748 \\
Congo & 2013 & 7863 \\
Benin & 2011 & 10996 \\
Ethiopia & 2016 & 8751 \\
Ghana & 2014 & 2561 \\
Guinea & 2012 & 3082 \\
Cote d'lvoire & 2011 & 2804 \\
Kenya & 2014 & 8607 \\
Lesotho & 2014 & 1195 \\
Madagascar & 2008 & 5096 \\
Malawi & 2016 & 4432 \\
Mali & 2012 & 4695 \\
Mozambique & 2011 & 8648 \\
Namibia & 2013 & 997 \\
Niger & 2012 & 5201 \\
Nigeria & 2013 & 26465 \\
Rwanda & 2014 & 3282 \\
South Africa & 2016 & 438 \\
Zimbabwe & 2015 & 4426 \\
Tanzania & 2015 & 7794 \\
Zambia & 2013 & 10785 \\
Total & & 145020 \\
\hline & &
\end{tabular}

warehousing approach to extract, transform and load data from numerous nationally representative surveys into a single-view schema to ensure that data sources become compatible. A total of twenty-six sub-Saharan African countries were initially extracted from the IPUMS website for analysis in the current study. Appendix 1 shows the characteristics of households as well as the characteristics of women and children under 5 years that were available for each country. Notably, $\mathrm{Hb}$ concentration readings for measuring anaemia were not captured for women in the Angola, Kenya, Nigeria, Zambia and Sudan data sets. Additionally, the Sudan data set had no indicator of nutritional status for women and children, while Angola had no data on nutritional status indicators for women. The final analytical sample therefore includes twenty-three countries with valid data on all variables of interest.

\section{Measurement of variables}

\section{Outcome variables}

The study focused on measuring five categories of household burden of malnutrition as dependent variables. These were undernutrition, overweight/obesity, anaemia (micronutrient deficiency), double burden and triple burden malnutrition. These conditions were measured among women (15-49 years) and children (6-59 months) in the household. Undernutrition among children was measured using height-for-age and weight for height $z$-scores, while overweight/obesity was measured using weight-for-height $z$-scores. Undernutrition and overweight/obesity among women were measured using BMI. Micronutrient deficiency was assessed using anaemia as an indicator, and this 
was measured using the $\mathrm{Hb}$ concentration of children under 5 years and women (15-49 years) in the household.

Household undernutrition also referred to as undernutrition only or undernourished households is characterised by households with either an undernourished child and or undernourished woman. A child is considered to be undernourished when she/he is either stunted (height-for-age $z$-scores $<-2$ ) or wasted (weight-for-height age $z$-scores $<-2)^{(38)}$. An undernourished woman is considered as one with a BMI $<18.5 \mathrm{~kg} / \mathrm{m}^{2}$. An overweight/obese household is characterised as a household having an overweight child and or an overweight/obese woman. An overweight child is one with a weight-for-height $z$-score $>2$, while an overweight/obese woman is one with a BMI $>24.9 \mathrm{~kg} / \mathrm{m}^{2(39)}$. Anaemic households are households with either an anaemic child or anaemic woman or both. Children with Hb concentration of $\leq 110-119 \mathrm{~g} / \mathrm{l}$ and women with $\mathrm{Hb}$ concentration of $\leq 100-109 \mathrm{~g} / 1$ were considered to be anaemic ${ }^{(39)}$.

Household-level double burden and triple burden malnutrition were based on the existence of a combination of the single conditions in the household. A household with DBM was considered as one having the co-occurrence of undernutrition and overweight/obesity in a child and or woman $^{(1)}$ as defined above. Households with TBM were those with the co-occurrence of undernutrition, overweight/obesity and anaemia ${ }^{(29)}$. For example, a household is classified as a triple burden malnutrition household if the there is an undernourished child who is also anaemic with an overweight/obese woman in the same household. Similarly, a household with an undernourished woman who is also anaemic and an overweight child is classified as triple burden malnutrition household. The classification of household DBM and TBM is thus driven primarily by the combination of the nutritional status of the children and women in the household.

\section{Independent variables}

The current study sought to examine household factors that influence household burden of malnutrition while controlling for the individual characteristics of women and children in the household. These household and individual factors therefore constitute the independent variables for the study. These include the age and sex of the household head, total number of household members (household size), household access to improved water and sanitation (toilet facilities) and the wealth quintile of the household. The location of the household was considered as whether households were in a rural or urban area. The available individual characteristics include the age of children (under 5 years) and women (15-49 years) in the household.

\section{Statistical analysis}

The characteristics of the study sample including the characteristics of the households and the women and children in the households were described using means and percentages. The various categories of household burden of malnutrition were categorised as binary outcomes, that is, households with an undernourished child and/or woman were classified as 1 and 0 otherwise, households with an overweight/obese child and/or woman are represented as 1 and 0 otherwise, households with either an anaemic child and or anaemic woman were represented as 1 and 0 otherwise. Similarly, households that qualify as having a double burden of malnutrition were assigned a score of 1 and 0 otherwise. The same scale was used for households that had triple burden malnutrition. Per these categorisation and given that the various types of household burden of malnutrition were categorised as binary outcomes, the analysis technique employed to explore the correlates of the various malnutrition outcomes was a binary logistic regression. All statistical analyses were performed using the Stata statistical software package version 14.2 (2017; StataCorp). Statistical significance was set at the $5 \% \alpha$-level $(P<0.05)$.

\section{Results}

\section{Characteristics of the study sample}

The households in the study had about seven members on average, and the average age of the head of the household was about 39 years (Table 2). The heads of the households were mostly males (84.4\%), and only about $6 \%$ of the household heads had higher than secondary level of education. In terms of conditions in the household, a little more than half of the households had improved sources of drinking water, while about two-fifths had improved toilet facilities. Generally, the proportion of households belonging to the various wealth quintiles decreased as wealth quintile increased. Specifically, about a quarter (24.5\%) of the households belonged to the poorest quintile compared with about $16 \%$ who belonged to the richest quintile. In terms of location of residence, about seven out of ten of the households were in rural areas. Children under 5 in the households were about 2 years and 4 month old on average and a little more than half were between 24 and 59 months old. Male children constituted a slightly higher proportion (50.5\%) compared with female children (49.5\%). Women in the reproductive age in the households were about 29 years old on average with those aged 45-49 years constituting the smallest proportion ( $2 \cdot 2 \%)$. Also, nearly all the women of reproductive age in the households were married or cohabiting (95.7\%) and about two-fifths (42.5\%) have not had any formal education, while about one-third had attained primary level of education (Table 2).

\section{Prevalence of malnutrition among women of reproductive age and under children 5}

The results in Table 3 show that a little more than one-third $(37 \cdot 2 \%)$ of the children under 5 involved in the study were stunted and about one in ten (9.9\%) were wasted, while 
Table 2 Characteristics of study population

\begin{tabular}{|c|c|c|}
\hline Variables & Mean \pm SD/percentage (\%) & Number \\
\hline \multicolumn{3}{|l|}{ Household characteristics } \\
\hline \multicolumn{2}{|l|}{ Household size (average) } & \multirow[t]{3}{*}{145020} \\
\hline Mean & $6 \cdot 75$ & \\
\hline $\mathrm{SD}$ & 0.01 & \\
\hline \multicolumn{2}{|l|}{ Age of household head (average) } & \multirow[t]{3}{*}{145020} \\
\hline Mean & 38.82 & \\
\hline SD & 0.03 & \\
\hline \multicolumn{3}{|l|}{ Sex of household head } \\
\hline Male & 84.4 & 122318 \\
\hline Female & $15 \cdot 6$ & 22702 \\
\hline \multicolumn{3}{|c|}{ Level of education attained by household head } \\
\hline No formal education & 34.9 & 50593 \\
\hline Primary & 32.7 & 47379 \\
\hline Secondary & $26 \cdot 1$ & 37811 \\
\hline Tertiary/higher & $6 \cdot 4$ & 9237 \\
\hline \multicolumn{3}{|l|}{ Main source of drinking water } \\
\hline Improved & $55 \cdot 7$ & 80748 \\
\hline Non-improved & $44 \cdot 3$ & 64272 \\
\hline \multicolumn{3}{|l|}{ Type of toilet facility } \\
\hline Unimproved & $59 \cdot 2$ & 85904 \\
\hline Improved & $40 \cdot 8$ & 59116 \\
\hline \multicolumn{3}{|l|}{ Wealth quintile } \\
\hline Poorest & 24.5 & 35555 \\
\hline Poorer & 21.4 & 30994 \\
\hline Middle & $19 \cdot 6$ & 28465 \\
\hline Richer & $18 \cdot 3$ & 26539 \\
\hline Richest & $16 \cdot 2$ & 23467 \\
\hline \multicolumn{3}{|l|}{ Location of household residence } \\
\hline Urban & 28.5 & 41392 \\
\hline Rural & 71.5 & 103628 \\
\hline \multicolumn{3}{|l|}{ Characteristics of children } \\
\hline \multicolumn{2}{|l|}{ Age continuous (average) } & \multirow[t]{3}{*}{145020} \\
\hline Mean & 28.60 & \\
\hline SD & 0.05 & \\
\hline \multicolumn{3}{|l|}{ Age (in months) } \\
\hline $0-5$ months & $10 \cdot 6$ & 15394 \\
\hline $6-11$ months & 10.9 & 15730 \\
\hline $12-23$ months & $20 \cdot 6$ & 29842 \\
\hline $24-60$ months & 57.9 & 84072 \\
\hline \multicolumn{3}{|l|}{ Sex } \\
\hline Male & 50.5 & 73219 \\
\hline Female & 49.5 & 71801 \\
\hline Characteristics of women & & \\
\hline Age (average) & & 145020 \\
\hline Mean & 29.4 & \\
\hline $\mathrm{SD}$ & 0.02 & \\
\hline Age (5-year groups) & & \\
\hline $15-19$ & 4.6 & 6607 \\
\hline $20-24$ & $20 \cdot 6$ & 29881 \\
\hline $25-29$ & $28 \cdot 2$ & 40851 \\
\hline $30-34$ & $22 \cdot \overline{3}$ & 32288 \\
\hline $35-39$ & $15 \cdot 1$ & 21924 \\
\hline $40-44$ & $7 \cdot 1$ & 10339 \\
\hline $45-49$ & $2 \cdot 2$ & 3130 \\
\hline Marital status & & \\
\hline Single & 4.3 & 6195 \\
\hline Married & 95.7 & 138825 \\
\hline Highest level of education attained & & \\
\hline No formal education & $42 \cdot 7$ & 61848 \\
\hline Primary & $34 \cdot 7$ & 50345 \\
\hline Secondary & $19 \cdot 7$ & 28516 \\
\hline Tertiary/Higher & 2.9 & 4311 \\
\hline Total & $100 \cdot 00$ & 145020 \\
\hline
\end{tabular}

about $5 \%$ were overweight/obese and about two-thirds (63.4\%) were anaemic. Additionally, about eight out of ten of the children under five were undernourished and anaemic, while $2 \cdot 1 \%$ were overweight and anaemic. Considering women in the reproductive age, one out of ten were underweight, while almost seven in ten were of 
Table 3 Prevalence of malnutrition in household

\begin{tabular}{|c|c|c|c|c|}
\hline Household population-group & Malnutrition status & Percentage (\%) & $95 \% \mathrm{Cl}$ & Number \\
\hline \multirow[t]{14}{*}{ Children } & Stunting & & & \\
\hline & Normal & $62 \cdot 8$ & $62 \cdot 5,63 \cdot 1$ & 83193 \\
\hline & Stunted & $37 \cdot 2$ & $36 \cdot 9,37 \cdot 5$ & 49301 \\
\hline & Wasting & & & \\
\hline & Normal & $90 \cdot 1$ & $90 \cdot 0,90 \cdot 3$ & 115484 \\
\hline & Wasting & 9.9 & $9 \cdot 7,10 \cdot 0$ & 12626 \\
\hline & Overweight/obesity & & & \\
\hline & Normal weight & $95 \cdot 1$ & $95 \cdot 0,95 \cdot 2$ & 121843 \\
\hline & Overweight & 4.9 & $4 \cdot 8,5 \cdot 0$ & 6267 \\
\hline & Anaemia & & & \\
\hline & Not anaemic & $36 \cdot 6$ & $36 \cdot 3,37 \cdot 0$ & 27477 \\
\hline & $\begin{array}{l}\text { Anaemic } \\
\text { Combined conditions }\end{array}$ & $63 \cdot 4$ & $63 \cdot 0,63 \cdot 7$ & 47504 \\
\hline & Undernutrition (stunted or wasted) + anaemic & $77 \cdot 9$ & $77 \cdot 6,78 \cdot 2$ & 52924 \\
\hline & Overweight + anaemic & $2 \cdot 1$ & $2 \cdot 0,2 \cdot 2$ & 1433 \\
\hline \multirow[t]{11}{*}{ Women } & $\mathrm{BMI}$ & & & \\
\hline & Underweight & 9.9 & $9 \cdot 7,10 \cdot 0$ & 14323 \\
\hline & Normal weight & 68.8 & $68 \cdot 6,69 \cdot 1$ & 99798 \\
\hline & Overweight & $15 \cdot 7$ & $15 \cdot 5,15 \cdot 9$ & 22753 \\
\hline & Obese & $5 \cdot 6$ & $5 \cdot 5,5 \cdot 7$ & 8146 \\
\hline & Anaemia & & & \\
\hline & Not anaemic & 58.7 & $58 \cdot 4,59 \cdot 0$ & 53069 \\
\hline & Anaemic & $41 \cdot 3$ & $41 \cdot 0,41 \cdot 6$ & 37333 \\
\hline & Combined conditions & & & \\
\hline & Overweight + anaemic & $6 \cdot 7$ & $6 \cdot 6,6 \cdot 9$ & 6084 \\
\hline \multirow{2}{*}{\multicolumn{5}{|c|}{ Household (Women + Children) }} \\
\hline & & & & \\
\hline & Undernutrition (Women + Children) & $5 \cdot 1$ & $5 \cdot 0,5 \cdot 2$ & 6490 \\
\hline & Overweight/obesity (Women + Children) & 1.5 & $1.4,1.6$ & 1933 \\
\hline & Anaemia (Women + Children) & $29 \cdot 4$ & $29 \cdot 1,29 \cdot 7$ & 21927 \\
\hline
\end{tabular}

normal weight and all together, about one in five were either overweight (15.7\%) or obese (5.6\%). Again, about every four out of ten of the women in the households involved in the study were anaemic. Furthermore, about $7 \%$ of the women were overweight and anaemic, while about $5 \%$ were underweight and anaemic (Table 3).

\section{Housebold burden of malnutrition}

The most common condition of malnutrition at the household level was anaemia which is characterised by the presence of either a child under 5 who is anaemic or a woman (15-49 years) who is anaemic or both. The results in Fig. 1 show that nearly seven out of ten households involved in the study had an anaemic child and or woman. The next most common condition of household malnutrition was undernutrition which is characterised by the presence of either an underweight, stunted or wasted child under 5 or an underweight woman or both. The results show that about one in two ( $45 \%$ ) of the households were undernourished households. Overweight/obese households which are characterised by a household having either an overweight/obese child under 5 or an overweight/obese woman or both was observed to be present in about one in four of the households. About $8 \%$ of the households were dual or double burden households, while about $5 \%$ were triple burden households. Additionally, about $5 \%$ of the households had an undernourished child and an undernourished woman, while about $2 \%$ had an

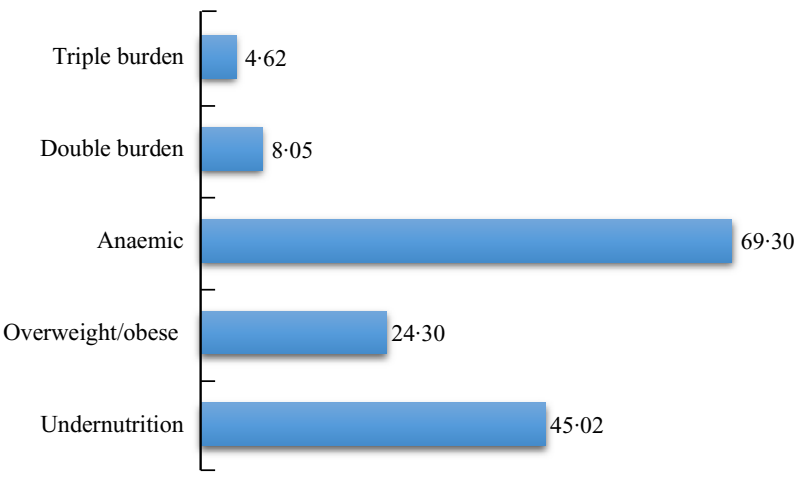

Fig. 1 (colour online) Percentage distribution of household burden of malnutrition

overweight/obese woman and an overweight/obese child. However, nearly a third (29.4\%) of the households had an anaemic child and an anaemic woman in the same household (Table 3).

The country-level results presented in Table 4 show wide variations in the burden of malnutrition across SSA. Anaemia is the most common burden of malnutrition, and the condition is highest in Burkina Faso (88.19\%), Mali (84.53\%), Cote d'Ivoire (82.19\%) and Guinea (81.86\%) and lowest in Rwanda (42.60\%). Undernutrition was highest in Burundi (60.96\%), Madagascar (54.98\%) and Ethiopia (54.36\%) and lowest in Ghana (26.55\%). Overweight/ obesity was highest in South Africa where about seven 
Table 4 Percentage distribution of household burden of malnutrition by country

\begin{tabular}{|c|c|c|c|c|c|}
\hline \multirow[b]{2}{*}{ Country } & \multicolumn{5}{|c|}{ Household burden of malnutrition(\%) } \\
\hline & Undernutrition & Overweight/obesity & Anaemia & Double burden & Triple burden \\
\hline Burkina Faso & 49.47 & $10 \cdot 75$ & 88.19 & $3 \cdot 74$ & 3.35 \\
\hline Burundi & $60 \cdot 96$ & $10 \cdot 61$ & $68 \cdot 29$ & 3.72 & $2 \cdot 19$ \\
\hline Cameroon & 37.97 & 34.04 & $70 \cdot 16$ & $8 \cdot 80$ & $6 \cdot 11$ \\
\hline Democratic Republic of Congo & $53 \cdot 81$ & $16 \cdot 86$ & $70 \cdot 34$ & 7.33 & 5.01 \\
\hline Benin & $39 \cdot 26$ & $33 \cdot 14$ & $68 \cdot 23$ & 13.99 & 8.51 \\
\hline Ethiopia & $54 \cdot 36$ & $11 \cdot 10$ & $65 \cdot 26$ & $3 \cdot 18$ & 2.04 \\
\hline Ghana & 26.55 & 37.02 & 74.75 & 5.78 & 4.55 \\
\hline Guinea & 41.69 & $20 \cdot 08$ & 81.86 & 5.68 & 4.59 \\
\hline Cote d'Ivoire & 35.52 & 23.32 & 82.15 & 6.03 & 4.68 \\
\hline Kenya & 37.63 & 28.57 & - & 6.56 & - \\
\hline Lesotho & 37.57 & 46.69 & $57 \cdot 78$ & $13 \cdot 81$ & 8.66 \\
\hline Madagascar & 54.98 & 5.46 & $62 \cdot 16$ & $1 \cdot 71$ & 1.09 \\
\hline Malawi & $39 \cdot 17$ & $24 \cdot 19$ & $66 \cdot 69$ & $7 \cdot 69$ & 4.89 \\
\hline Mali & $46 \cdot 84$ & $19 \cdot 72$ & 84.53 & $6 \cdot 69$ & $5 \cdot 61$ \\
\hline Mozambique & 44.55 & 21.66 & 64.71 & 8.37 & $5 \cdot 20$ \\
\hline Namibia & $30 \cdot 29$ & 36.91 & 51.41 & $7 \cdot 02$ & 4.43 \\
\hline Niger & $52 \cdot 11$ & $22 \cdot 01$ & 78.20 & 8.56 & $6 \cdot 81$ \\
\hline Nigeria & $47 \cdot 22$ & 28.03 & - & $10 \cdot 10$ & - \\
\hline Rwanda & $40 \cdot 37$ & $30 \cdot 41$ & $42 \cdot 60$ & 9.72 & $4 \cdot 30$ \\
\hline South Africa & $24 \cdot 20$ & 74.66 & $56 \cdot 27$ & $17 \cdot 12$ & $10 \cdot 49$ \\
\hline Zimbabwe & $29 \cdot 17$ & 41.82 & $45 \cdot 73$ & 9.60 & $4 \cdot 64$ \\
\hline Tanzania & $40 \cdot 22$ & 28.42 & 71.07 & $8 \cdot 61$ & 5.98 \\
\hline Zambia & $45 \cdot 74$ & $24 \cdot 75$ & - & $9 \cdot 61$ & - \\
\hline Total & 45.02 & $24 \cdot 14$ & $69 \cdot 30$ & 8.02 & 4.60 \\
\hline
\end{tabular}

out of every ten households had an overweight/obese woman and or child. The proportion of overweight/obese households observed in South Africa was about three times higher the global SSA figure of $24 \cdot 14 \%$. Lesotho recorded the next highest proportion of households with an overweight/ obese woman and or child (46.69\%) and again this was about twice the global SSA figure. Madagascar recorded the lowest proportion $(5.46 \%)$ of households with overweight/obese women and or children. In general, double and triple burden malnutrition was less common compared with the single conditions. DBM and TBM were highest is South Africa (17.12\%), Benin (13.99\%) and Lesotho (13.81\%) and lowest in Madagascar (1.71\%). Similarly, TBM was highest in South Africa (10.49\%) and Lesotho (8.66\%) and lowest again in Madagascar (1.09\%).

\section{Housebold factors as predictors of bousebold burden of malnutrition}

The results presented in Table 5 show that the older the head of the household, the lower the chances of the household having a woman and or a child who is undernourished but the higher the likelihood of the household having an overweight/obese woman and or child. Also, the chances of a household having an anaemic child and or woman was about $2 \%$ higher for each additional increase in the age of the head of the household. The age of the household head was, however, not significantly associated with the household experiencing double or triple burden of malnutrition. The sex of the household head on the other hand did not show a significant association with any of the conditions of household burden of malnutrition. Household size on the other hand was associated with the single conditions of household burden of malnutrition. Increasing household size was associated with a higher likelihood of undernutrition and anaemia but a lower likelihood of overweight/ obesity at the household level. The results further reveal that unimproved source of drinking water was associated with a lower likelihood of a household being an anaemic or triple burden household. The state of sanitation in the household, that is, whether the household had an improved or unimproved toilet facility was significantly associated with some conditions of household burden of malnutrition. Specifically, households that have improved toilet facilities were more likely to have a child or adult woman who is overweight/obese but less likely to be undernourished. Households with improved toilet facilities also had a higher chance of being double and triple burden malnutrition households.

The results with regard to household wealth status indicate that, on the one hand one, increasing household wealth status was associated with a lower likelihood of a household being undernourished or anaemic, but on the other hand, increasing household wealth was associated with a higher likelihood of the household being overweight/obese. Similarly, the chances of a household being a dual burden malnutrition household increased with increasing household wealth but considering triple burden of malnutrition, only households in the richer wealth category were found to be at increased risk. The location of a household, whether rural or urban, was found to be associated with undernutrition such that rural households were more likely to be undernourished. However, rural 


\section{Public Health Nutrition}

Table 5 Results of binary logistic regression analysis showing the odds ratios of the association between household characteristics and household burden of malnutrition

\begin{tabular}{|c|c|c|c|c|c|c|c|c|c|c|}
\hline \multirow[b]{2}{*}{ Variables } & \multicolumn{10}{|c|}{ Odds ratios } \\
\hline & $\begin{array}{l}\text { Undernutrition } \\
(n 145020)\end{array}$ & $95 \% \mathrm{Cl}$ & $\begin{array}{l}\text { Overweight/ } \\
\text { obesity } \\
(n 145020)\end{array}$ & $95 \% \mathrm{Cl}$ & $\begin{array}{l}\text { Anaemia } \\
(n 90783)\end{array}$ & $95 \% \mathrm{Cl}$ & $\begin{array}{l}\text { Double burden } \\
(n 145020)\end{array}$ & $95 \% \mathrm{Cl}$ & $\begin{array}{l}\text { Triple Burden } \\
\text { (n } 90783)\end{array}$ & $95 \% \mathrm{Cl}$ \\
\hline $\begin{array}{l}\text { Age of household head } \\
\text { Sex of household head } \\
\text { [Male] }\end{array}$ & 0.997 & $0.996,0.999^{\star \star \star}$ & 1.006 & $1 \cdot 005,1 \cdot 008^{\star \star \star}$ & 1.002 & $1.000,1.003^{*}$ & 1.002 & $1.000,1.004$ & 1.003 & $0.999,1.006$ \\
\hline Female & 0.970 & $0.932,1.010$ & 0.985 & $0.940,1.032$ & 0.988 & $0.940,1.037$ & 0.931 & $0.867,1.000$ & 0.965 & $0.870,1 \cdot 070$ \\
\hline $\begin{array}{l}\text { Household size } \\
\text { Household drinking } \\
\text { water [Improved] }\end{array}$ & 1.013 & $1 \cdot 009,1 \cdot 018^{\star *}$ & 0.980 & $0.974,0.986^{\star \star \star}$ & 1.028 & $1.021,1.035^{\star \star *}$ & 0.996 & $0.988,1.004$ & 0.995 & $0.983,1.009$ \\
\hline $\begin{array}{l}\text { Unimproved } \\
\text { Toilet facility/sanitation } \\
\text { [Unimproved] }\end{array}$ & 0.980 & $0.953,1.008$ & 0.999 & $0.996,1.033$ & 0.960 & $0.925,0.996^{*}$ & 0.954 & $0.908,1.002$ & 0.909 & $0.841,0.982^{*}$ \\
\hline $\begin{array}{l}\text { Improved } \\
\text { Wealth status [Poorest] }\end{array}$ & 0.962 & $0.933,0.993^{*}$ & $1 \cdot 193$ & $1 \cdot 150,1 \cdot 238^{\star \star \star}$ & 1.004 & $0.963,1.046$ & $1 \cdot 153$ & $1 \cdot 092,1 \cdot 217^{\star \star \star}$ & $1 \cdot 179$ & $1 \cdot 079,1 \cdot 287^{\star \star \star}$ \\
\hline Poorer & 0.829 & $0.797,0 \cdot 862^{\star \star \star}$ & 1.423 & $1.346,1 \cdot 504^{\star \star \star}$ & 0.811 & $0.768,0 \cdot 856^{\star \star \star}$ & 1.236 & $1 \cdot 145,1 \cdot 333^{\star \star \star}$ & $1 \cdot 103$ & $0.980,1 \cdot 242$ \\
\hline Middle & 0.720 & $0.691,0.750^{\star \star \star}$ & 1.747 & $1.652,1.849^{\star \star \star}$ & 0.767 & $0.726,0.812^{\star \star \star}$ & 1.298 & $1 \cdot 199,1 \cdot 404^{\star \star \star}$ & $1 \cdot 113$ & $0.988,1.254$ \\
\hline Richer & 0.604 & $0.577,0.633^{\star \star *}$ & $2 \cdot 375$ & $2 \cdot 238,2 \cdot 520^{\star \star \star}$ & 0.679 & $0.640,0.721^{\star \star *}$ & 1.409 & $1 \cdot 294,1 \cdot 535^{\star \star *}$ & $1 \cdot 224$ & $1 \cdot 078,1 \cdot 389^{\star *}$ \\
\hline $\begin{array}{l}\text { Richest } \\
\text { Location [Urban] }\end{array}$ & 0.449 & $0.423,0.476^{\star \star \star}$ & $3 \cdot 788$ & $3.531,4 \cdot 063^{\star * *}$ & 0.562 & $0.522,0.605^{\star * *}$ & 1.507 & $1.358,1 \cdot 673^{* * *}$ & $1 \cdot 171$ & $0.997,1.376$ \\
\hline $\begin{array}{l}\text { Rural } \\
\text { Children (under five) } \\
\text { Age of child in months } \\
{[0-5]}\end{array}$ & 1.055 & $1.016,1 \cdot 096^{\star \star}$ & 0.838 & $0 \cdot 804,0 \cdot 874^{\star \star \star}$ & 0.935 & $0 \cdot 887,0.986^{\star}$ & 0.934 & $0.887,0.995^{\star}$ & 0.975 & $0.873,1.089$ \\
\hline 6-11 months & 1.453 & $1 \cdot 369,1 \cdot 543^{\star \star \star}$ & 0.743 & $0.693,0.796^{\star \star \star}$ & $5 \cdot 196$ & $4 \cdot 808,5 \cdot 616^{\star \star \star}$ & 0.838 & $0.755,0.931^{\star *}$ & 1.350 & $1 \cdot 123,1 \cdot 622^{* *}$ \\
\hline 12-23 months & $2 \cdot 319$ & $2 \cdot 199,2 \cdot 445^{\star \star \star}$ & 0.692 & $0.652,0.735^{\star \star \star}$ & 4.658 & $4 \cdot 365,4 \cdot 970^{\star \star \star}$ & 0.944 & $0.863,1.032$ & 1.616 & $1.376,1 \cdot 897^{\star \star \star}$ \\
\hline $24-60$ months & $2 \cdot 295$ & $2 \cdot 129,2 \cdot 342^{\star \star \star}$ & 0.793 & $0.752,0.836^{\star \star \star}$ & $2 \cdot 809$ & $2 \cdot 658,2 \cdot 968^{\star * *}$ & 1.019 & $0.942,1 \cdot 103$ & 1.631 & 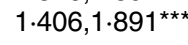 \\
\hline $\begin{array}{l}\text { Women's Characteristics } \\
\text { Age [15-19] }\end{array}$ & & & & & & & & & & \\
\hline $20-24$ & 0.833 & $0.777,0.892^{\star \star \star}$ & 1.406 & $1 \cdot 266,1 \cdot 561^{\star \star \star}$ & 0.964 & $0.881,1.054$ & 1.048 & $0.916,1.199$ & 0.856 & $0.698,1.050$ \\
\hline $25-29$ & 0.727 & $0.679,0.778^{* * *}$ & 1.993 & $1 \cdot 799,2 \cdot 207^{\star \star *}$ & 0.878 & $0.804,0.960^{\star *}$ & $1 \cdot 186$ & $1.040,1 \cdot 352^{\star}$ & $1 \cdot 132$ & $0.929,1 \cdot 378$ \\
\hline $30-34$ & 0.710 & $0.663,0.762^{\star \star \star}$ & 2.675 & $2 \cdot 412,2 \cdot 965^{\star \star \star}$ & 0.824 & $0.752,0.902^{\star \star \star}$ & 1.442 & $1 \cdot 262,1 \cdot 647^{\star \star \star}$ & $1 \cdot 155$ & $0.945,1.411$ \\
\hline $35-39$ & 0.704 & $0.655,0 \cdot 758^{\star \star \star}$ & $3 \cdot 209$ & $2 \cdot 886,3 \cdot 567^{\star \star \star}$ & 0.826 & $0.751,0.909^{\star \star \star}$ & 1.566 & $1 \cdot 366,1 \cdot 795^{\star \star *}$ & 1.257 & $1 \cdot 023,1 \cdot 546^{\star}$ \\
\hline $40-44$ & 0.667 & $0.615,0 \cdot 724^{\star \star \star}$ & 3.312 & $2 \cdot 955,3 \cdot 712^{\star \star \star}$ & 0.773 & $0.694,0 \cdot 861^{\star \star \star}$ & 1.609 & $1 \cdot 385,1 \cdot 869^{\star \star \star}$ & 1.443 & $1 \cdot 155,1 \cdot 803^{\star \star}$ \\
\hline $45-49$ & 0.684 & $0.613,0.764^{\star \star \star}$ & 3.385 & $2 \cdot 935,3.903^{\star \star \star}$ & 0.796 & $0.686,0.925^{\star \star}$ & 1.786 & $1 \cdot 479,2 \cdot 157^{\star \star \star}$ & 1.385 & $1.0341857^{*}$ \\
\hline Marital status [Single] & & & & & & & & & & \\
\hline $\begin{array}{l}\text { Married/Cohabiting } \\
\text { Level of educational } \\
\text { attainment [No } \\
\text { education] }\end{array}$ & 0.929 & $0.856,0.999$ & $1 \cdot 276$ & $1 \cdot 167,1 \cdot 397^{\star \star \star}$ & 1.041 & $0 \cdot 946,1 \cdot 146$ & 1.094 & $0.959,1 \cdot 247$ & 1.063 & $0.875,1 \cdot 292$ \\
\hline Primary & 0.759 & $0.735,0.784^{\star \star \star}$ & 1.219 & $1 \cdot 171,1 \cdot 269^{\star \star \star}$ & 0.811 & $0.776,0.847^{\star \star \star}$ & 0.979 & $0.923,1.037$ & 1.089 & $0.990,1 \cdot 199$ \\
\hline Secondary & 0.583 & $0.558,0.608^{\star \star *}$ & 1.526 & $1.451,1.604^{\star \star \star}$ & 0.751 & $0.708,0.797^{\star \star *}$ & 0.951 & $0.881,1.026$ & 1.029 & $0.905,1.169$ \\
\hline $\begin{array}{l}\text { Tertiary/Higher } \\
\text { Year of survey [2008] }\end{array}$ & 0.379 & $0.341,0 \cdot 420^{\star \star \star}$ & $2 \cdot 150$ & $1 \cdot 962,2 \cdot 355^{\star \star \star}$ & 0.549 & $0.478,0.630^{\star \star \star}$ & 0.735 & $0 \cdot 629,0 \cdot 860^{\star \star \star}$ & 0.545 & $0.374,0 \cdot 793^{* *}$ \\
\hline 2010 & 0.770 & $0.703,0.844^{* \star *}$ & 2.045 & $1 \cdot 717,2 \cdot 436^{\star \star \star *}$ & 3.797 & $3 \cdot 388,4 \cdot 254^{\star * *}$ & 1.936 & $1.437,2 \cdot 608^{\star \star \star}$ & 2.789 & $1.958,3 \cdot 972^{\star \star \star}$ \\
\hline 2011 & 0.574 & $0.533,0.619^{\star \star \star}$ & 7.562 & $6 \cdot 494,8 \cdot 805^{\star \star \star}$ & $1 \cdot 109$ & $1.023,1.202^{*}$ & 6.717 & $5 \cdot 173,8 \cdot 722^{\star \star *}$ & 5.659 & $4 \cdot 109,7 \cdot 793^{\star \star \star}$ \\
\hline 2012 & 0.772 & $0.711,0.838^{\star \star \star}$ & 4.376 & $3 \cdot 733,5 \cdot 129^{\star \star \star}$ & $2 \cdot 129$ & $1.941,2 \cdot 335^{\star \star \star}$ & $4 \cdot 108$ & $3 \cdot 136,5 \cdot 382^{\star \star \star}$ & $5 \cdot 341$ & $3 \cdot 851,7 \cdot 409^{\star \star \star}$ \\
\hline
\end{tabular}


households were less likely to be overweight/obese, anaemic or double burden malnutrition households.

Considering the characteristics of reproductive age women and under 5 children in the household, the findings indicate that the chances of a household having an undernourished child and or an underweight woman increases with increasing age of a child under 5 , but the chances of a household having an overweight/obese adult woman and or child decreased with increasing age of a child under 5. Additionally, there was a higher likelihood of a household having an anaemic child and or anaemic woman with increasing age of a child under 5; however, the odds was lower at older ages for the child. There was a lower likelihood of a household having a double burden of malnutrition with increasing age of a child under 5 from 6 to 23 months, but statistical significance was only achieved for infants who were aged 6 to 11 months compared with 0-5-month-old infants. Again, the chances of a household having a triple burden of malnutrition generally increased with increasing age of a child under 5 in the household.

Considering the age of women in the reproductive age in the household, the findings indicate that the chances of a household being an undernourished household decreased with increasing age of women from age 20 to 49 years. Similar results were observed for anaemia, but the results were only statistically significant for women aged 25-49 years. The chances of a household being overweight/obese was observed to increase with increasing age of reproductive age women in the household. Again, the chances of a household having a double or triple burden of malnutrition increased with increasing age of reproductive age women from age 25 to 49 and 35 to 49 years, respectively, compared with when a woman in the household is 15-19 years old. The marital status of women in the household only showed a statistically significant association with the chances of a household being overweight/obese. Households with a woman in the reproductive age who was married showed a $26.7 \%$ higher chance of being overweight/obese. Also, increasing level of education among women of reproductive age in the household was associated with a lower likelihood of the household being undernourished or anaemic, but increasing level of education among reproductive age women in the household was associated with increased likelihood of a household being overweight/obese. However, considering the level of education of women in the reproductive age in the household and household double and triple burden of malnutrition, only tertiary level of education (among women in the reproductive age) was observed to be associated with a lower likelihood of a household having a double or triple burden of malnutrition.

Finally, the chances of a household being undernourished decreased in more recent survey years except in 2016, whereas the chances of a household being 
overweight/obese or anaemic or having a double or triple burden of malnutrition increased in recent survey years.

\section{Discussion}

The current study sought to examine the correlates of different classifications of household burden of malnutrition in SSA. To the best of our knowledge, this is the largest analysis examining household covariates of various conditions of malnutrition; undernutrition, overweight/obesity and anaemia and the co-occurrence of these conditions in the same household, using nationally representative data across sub-Saharan African.

The findings suggest that despite the stereotype image of skeletal children with severe hunger in SSA, the current study like many others, shows that overweight/obesity is also a public health concern in this region ${ }^{(33,40)}$. Our results show that micronutrient deficiency measured as anaemia is the commonest burden of malnutrition among women (15-49 years) and children under 5 in households across SSA. This burden of anaemia corroborates with studies conducted in Arab and Middle East countries ${ }^{(41,42)}$. Reasons for the high prevalence of anaemia in the SSA region are multifaceted. Besides low intake of iron-rich foods, factors such as inadequate hygiene and sanitary conditions are documented as contributors to anaemia in this region. Additionally, conditions such as glucose-6-phosphate dehydrogenase deficiency, haemoglobinopathies endemic diseases such as malaria and sickle cell all contribute significantly to the regions' anaemia prevalence ${ }^{(43-45)}$. The present study reveals that undernutrition occurs in one in two households, while overweight/obesity was present in about one in every four households in SSA. The results of the current study suggest that the prevalence of single conditions of malnutrition is comparatively higher than double and triple burden of malnutrition. However, the level of DBM as found in the current study is comparable to the level in Nepal $(6.60 \%)^{(46)}$. This notwithstanding, an earlier study conducted in Bangladesh, Nepal, Pakistan and Myanmar found the level of household DBM to be slightly lower than that of the present study ${ }^{(47)}$, but the level of TBM as was found in the present study is slightly lower (4.6\%) than what was found in Nepal (7.0\%) by Sunuwar et al. ${ }^{(46)}$.

In addition to the levels of household burden of malnutrition, which was realised, the results indicate that the prevalence of the various forms of household burden of malnutrition and their underlying household influencing factors are different. For example, whereas increasing age of the household head was associated with a lower likelihood of the household being undernourished, the same variable was associated with a higher likelihood of the household being overweight/obese and anaemic. But unlike the age of the household head, the sex of the head of the household head was not associated with any of the forms of household burden of malnutrition. This is contrary to a study conducted in Indonesia that reported some nutritional inequality among female-headed households ${ }^{(48)}$. The size of the household on the other hand was associated with a higher likelihood of undernutrition and anaemia as has been found in other studies ${ }^{(49)}$. These findings are plausible because increasing household size affects access to food such as fruits, vegetables ${ }^{(50)}$, meat and fish which tend to be relatively more expensive. The absence or reduction of such foods contributes significantly to iron-deficiency, causing anaemia. Household size was, however, found to be associated with a lower likelihood of the household having either an overweight/obese woman or child or both. Other household characteristics such as the type of toilet facility was found to be associated with the household's likelihood of having either an overweight/obese woman or child and also double and triple burden of malnutrition in the household. The mechanism of impact of type of toilet facility on the household burden of malnutrition as found in the present study could be operating through wealth or socio-economic status. Households with improved toilet facilities tend to be relatively wealthier compared with households with unimproved toilet facilities, and such wealthier households have been found to have higher burden of overweight/obesity, especially among women, and this could be what is driving the household burden of overweight/obesity, double and triple burden of malnutrition as was observed in the present study.

In terms of household wealth status, the results indicate that while richer households are less likely to be undernourished or anaemic, they are more likely to be overweight/obese and also, have double burden or triple burden malnutrition conditions. Similar findings have been reported in Nepal where mothers from the richest households were more likely to have double or triple burden of malnutrition ${ }^{(46)}$. Some of the plausible reasons for this finding are that while rich households may be more food secure $^{(34,51)}$ and also benefit from a more diverse diet, thus reducing the risk of undernutrition and micronutrient deficiency, rich households are also at a higher risk of overweight/obesity due to consumption of energy-dense foods and lower levels of physical activity. The location of a household, whether rural or urban, was also found to be associated with household burden of malnutrition. Rural households were found to have a lower likelihood of being overweight/obese or anaemic. Contrarily, other studies in some SSA countries, for example Ghana found that rural residence is associated with a high likelihood of micronutrient deficiency ${ }^{(34)}$. Another study conducted in the Gambia did not find significant difference in anaemia among non-pregnant females by residence ${ }^{(52)}$. These results do show the possible variability in the conditions contributing to anaemia in the region.

The present study found that increasing age of children under 5 years was associated with a higher likelihood of 
household TBM contrary to the findings of Sunuwar and colleagues in Nepal ${ }^{(46)}$, while in Pakistan and Myanmar, Anik and colleagues found that child's age (24-59 months) was associated with a higher likelihood of the household experiencing a double burden of malnutrition ${ }^{(47)}$. Additionally, the present study found that child's age was significantly associated with a higher likelihood of the household being undernourished as was found in Sierra Leone before the Ebola outbreak ${ }^{(53)}$. The effect of the age of children on the household burden of malnutrition could be a result of child feeding practices especially during complementary feeding and the weaning period. Poor feeding practices, feeding children with poor quality and or unbalanced diets and unhygienic feeding practices in the complementary feeding/weaning period increase the likelihood of undernutrition and micronutrient deficiency among children, and this contributes to the household burden of malnutrition.

Considering the characteristics of reproductive age women who are members of the household, the findings with regard to their age were as expected and similar findings have been found among women in $\mathrm{Nepal}^{(46)}$. Increasing age among women was associated with a higher chance of the household experiencing double and triple burden of malnutrition. The higher chance of overweight and obesity among older women in sub-Saharan Africa $^{(54)}$ is one of the possible drivers of the higher likelihood of household DBM and TBM as was found in the present study. Again, being in a marital union (for women of reproductive age) was found to be associated with a higher chance of the household being overweight/obese. This could also be because of the higher likelihood of married/cohabiting women being overweight/obese compared with their counterparts who are not married or in union. The level of education of women in the household also showed expected results. Higher level of education among women in the household was associated with a lower likelihood of the household being undernourished or anaemic on one hand but a higher likelihood of household overweight/obesity on the other hand. This pattern of results is likely being driven by other mechanisms influenced by education. For example, educated women are more likely to be employed and or gain income and thus they can contribute to meeting the food expenditure needs of their household which lowers the risk of food insufficiency thereby reducing the chances of undernutrition while also ensuring that the household consumes a balanced and diversified diet and thereby reducing the chances of micronutrient deficiency. But on the other hand, households with educated women may also be at risk of having overweight/obese individuals because of frequent consumption of high calorie energy-dense foods such as polished rice, sweetened carbonated drinks and high-fat high sugar snacks.

The findings regarding the year the survey was conducted gives indication of the ongoing nutrition transition in sub-Saharan Africa. The chances of household undernutrition generally decreased in more recent years, whereas the chances of overweight/obesity and anaemia increased in recent years. Again, the chances of double and triple burden of malnutrition were found to increase in more recent years. Changing dietary behaviours from consumption of nutritious staple/traditional diets rich in fibre and complex carbohydrates to the consumption of high calorie, energydense, fatty foods and food with simple sugars in recent years could be contributing to the higher likelihood of overweight/obesity and anaemia and the higher risk of double and triple burden of malnutrition in households in SSA. The high prevalence and higher likelihood of anaemia is particularly concerning. Governments of SSA countries and the international community need to pay attention to this as emphasised by Jiwani et al. ${ }^{(55)}$.

In tackling the double and triple burden of malnutrition, the WHO suggests 'Double-duty' actions ${ }^{(56)}$. These can be achieved through integrated initiatives, policies and programmes involving different sectors such as the various health and agricultural sectors in countries. Thus, working within 'institutional silos' should be avoided as much as possible when addressing the double and triple burden of malnutrition.

The findings of the current study reveal some important findings about the dynamics between household factors and household burden of malnutrition. The current study is one of the few studies that uses nationally representative data across SSA to investigate correlates of household burden of malnutrition from the perspective of influencing household factors. Other studies have mostly investigated individual-level risk factors while controlling for some household characteristics. The current study is also among the few studies that attempt to investigate the prevalence and influencing factors of double and triple burden of malnutrition at the household level across SSA. The study is, however, challenged by some limitations. For example, it would have been helpful to include dietary diversity at the household level in the analysis but not all countries collected data on this indicator; therefore, household dietary diversity could not be included in the analysis. Including this variable in the analysis if it was available may have given some more insights into the findings of the present study. Another limitation with the current study is the use of anaemia as the only indicator of micronutrient deficiency. It will be helpful for future research to measure other indicators of micronutrient deficiency if such data are available. Additionally, the use of IPUMS data has some limitations due to the differing content of questionnaires used in different countries and the suppression of low-level geographic detail. The latter is, however, done to protect confidentiality of respondents. Additionally, although the DHS to a large extent has consistent variables that are collected across the participating countries, there are some variables that may be missing or collected differently. This presents a situation where the sample (number of 
respondent) may vary during pooled data analysis as was the case in the present study. These challenges notwithstanding, the current study provides insights into the prevalence and household factors that influence the burden of malnutrition at the household level in subSaharan Africa.

\section{Conclusion}

The findings of the current study reveal a high prevalence of various forms of household burden of malnutrition particularly the single burden of anaemia, undernutrition and overweight/obesity. The findings further indicate that undernutrition and now overweight/obesity are not the only forms of malnutrition that affect households in SSA. Anaemia is indeed a persistent problem that needs urgent policy attention. Although rapid economic development and urbanisation in the SSA region has created favourable conditions for overweight/obesity, the persistence of poverty and poor access to resources continue to drive the prevalence of anaemia and undernutrition, and the co-existence of extreme spectrums of malnutrition, i.e. double and triple burden of malnutrition in the same household. Though individuals and/or households may respond differently to similar diet and lifestyles, diet quality is a major factor influencing single, double and triple burden of malnutrition ${ }^{(57)}$. Efficiently managing household double and triple burden of malnutrition will require a life-course approach as suggested by Darnton-Hill et al. ${ }^{(58)}$. This is important because undernutrition among children could result in overweight/obesity in later adult years, and undernourished women are likely to give birth to underweight children who are at risk of becoming overweight/ obese in later years. Unfortunately, knowledge of the current scenario of DBM and TBM has not necessarily translated in concrete policy action in some countries. For example, even though the 'Roadmap for Nutrition in South Africa 2013-2017' and Ghana's 'National Nutrition Policy For Ghana 2013$2017^{(59,60)}$ both acknowledge the presence of both under and overweight/obesity, no clear recommendation is provided towards curbing their co-occurrence in same households. It thus goes without saying that nutrition programming interventions need to address both undernutrition which is dominated by childhood stunting and increasing overweight/obesity among both children and adults and the co-existence of all these conditions in the same household if SSA is to achieve success in combating the burden of malnutrition in the region.

\section{Acknowledgements}

Acknowledgements: The authors are grateful to IPUMS DHS for granting access to the data. Financial support: 'This research received no specific grant from any funding agency, commercial or not-for-profit sectors'. Conflict of interest: There are no conflicts of interest. Authorship: A.K.C. and F.A.A.D. conceptualised the study. A.K.C. extracted the data and wrote the first draft of the introduction, methodology and conclusion. F.A.A.D. conducted the analysis and wrote the first draft of the abstract and discussion. Both authors reviewed the draft of the manuscript and approved the final version of the manuscript. Ethics of buman subject participation: The current study analysed secondary data from DHS. In accordance with ethics of conducting research with human subjects, voluntary consent to participate in the survey was sought from respondents prior to being interviewed by fieldworkers who were trained to conduct interviews. IPUMS DHS granted access to the data.

\section{Supplementary material}

For supplementary material accompanying this paper visit https://doi.org/10.1017/S1368980021001750

\section{References}

1. Popkin B, Orvalan C \& Grummer-Strawn LM (2020) Dynamics of the double burden of malnutrition and the changing nutrition reality. Lancet 395, 65-74.

2. Sheets LR, Tang CY \& Woldu HG (2019) The paradox of female obesity in low and lower-middle income countries. medRxiv 19003004.

3. Tzioumis E \& Adair LS (2014) Childhood dual burden of under- and overnutrition in low- and middle-income countries: a critical review. Food Nutr Bull 35, 230-243.

4. Doak CM, Adair LS, Bentley M et al. (2005) The dual burden household and the nutrition transition paradox. Int JObes $\mathbf{2 9}$, 129-136.

5. Swinburn BA, Sacks G, Hall KD et al. (2011) The global obesity pandemic: shaped by global drivers and local environments. Lancet 378, 804-814.

6. FAO, IFAD, UNICEF et al. (2019) The State of Food Security and Nutrition in the World 2019. Safeguarding against Economic Slowdowns and Downturns. Rome: FAO.

7. Popkin BM (2001) Nutrition transition and obesity in the developing world. J Nutr 131, 871S-873S.

8. Popkin BM (1998) The nutrition transition and its health implications in lower-income countries. Public Health Nutr 1, 5-21.

9. Freudenberg N \& Galea S (2008) The impact of corporate practices on health: implications for health policy. J Public Health Policy 29, 86-104.

10. Freudenberg N (2012) The manufacture of lifestyle: the role of corporations in unhealthy living. J Public Health Policy 33 , 244-256.

11. Kickbusch I (2012) Addressing the interface of the political and commercial determinants of health. Health Promot Int 27, 427-428.

12. Hastings G (2012) Why corporate power is a public health priority. BMJ 345, e5124.

13. Kotir JH (2011) Climate change and variability in SubSaharan Africa: a review of current and future trends and impacts on agriculture and food security. Environ Dev Sustain 13, 587-605. 
14. Swinburn BA, Kraak VI, Allender S et al. (2019) The global syndemic of obesity, undernutrition, and climate change: the lancet commission report. Lancet 393, 791-846.

15. Zhang N, Bécares L \& Chandola T (2016) Patterns and determinants of double-burden of malnutrition among rural children: evidence from China. PLoS One 11, e0158119.

16. Fongar A, Gödecke T \& Qaim M (2019) Various forms of double burden of malnutrition problems exist in rural Kenya. BMC Public Health 19, 1543.

17. Jingi AM, Kuate-Mfeukeu L, Hamadou B et al. (2018) Prevalence and associates of anemia in adult men and women urban dwellers in Cameroon: a cross-sectional study in a Sub-Saharan setting. Ann Blood 3, 34-34.

18. World Health Organization Regional Office for Africa (2017) Nutrition in the WHO African Region. https://www.afro. who.int/sites/default/files/2017-11/Nutrition\%20in\%20the\% 20WHO\%20African\%20Region\%202017_0.pdf（accessed March 2021)

19. World Health Organization (2021) Anaemia. https://www. who.int/health-topics/anaemia\#tab=tab_1 (accessed March 2021).

20. Olivares M, Walter T, Hertrampf E et al. (1999) Anaemia and iron deficiency disease in children. Br Med Bull 55, 534-543.

21. Desalegn Wolide A, Mossie A \& Gedefaw L (2014) Nutritional iron deficiency anemia: magnitude and its predictors among school age children, southwest Ethiopia: a community based cross-sectional study. PLoS One $\mathbf{9}$, e114059.

22. Kassebaum NJ, Jasrasaria R, Naghavi M et al. (2014) A systematic analysis of global anemia burden from 1990 to 2010. Blood 123, 615-624.

23. The Lancet (2016) GBD 2015: from big data to meaningful change. Lancet 388, 1447.

24. Dewey KG \& Begum K (2011) Long-term consequences of stunting in early life. Matern Child Nutr 7, 5-18.

25. Black RE, Victora CG, Walker SP et al. (2013) Maternal and child undernutrition and overweight in low-income and middle-income countries. Lancet 382, 427-451.

26. Persson M \& Persson B (2018) Maternal overweight and obesity in pregnancies complicated by type 1 diabetes. In Nutrition and Diet in Maternal Diabetes, pp. 49-58 [R Rajendram, V Preedy and V Patel, editors]. Cham, Switzerland: Springer International Publishing AG.

27. World Health Organization (2021) The double burden of malnutrition. https://www.who.int/nutrition/double-burdenmalnutrition/en/\#: :text=The\%20double\%20burden\%20of\% 20 malnutrition,populations $\% 2 \mathrm{C} \% 20$ and $\% 20$ across $\% 20$ the $\%$ 20lifecourse (accessed March 2021).

28. Hauqe SE, Sakisaka K \& Rahman M (2019) Examining the relationship between socioeconomic status and the double burden of maternal over and child under-nutrition in Bangladesh. Eur J Clin Nutr 73, 531-540.

29. Pinstrup-andersen P (2007) Agricultural research and policy for better health and nutrition in developing countries: a food systems approach. Agric Econ 37, 187-198.

30. Meenakshi JV (2016) Trends and patterns in the triple burden of malnutrition in India. Agric Econ 47, 115-134.

31. Freire WB, Silva-Jaramillo KM, Ramírez-Luzuriaga MJ et al. (2014) The double burden of undernutrition and excess body weight in Ecuador. Am J Clin Nutr 100, 1636S-1643S.

32. Jehn M \& Brewis A (2009) Paradoxical malnutrition in mother-child pairs: untangling the phenomenon of overand under-nutrition in underdeveloped economies. Econ Hum Biol 7, 28-35.

33. Amugsi DA, Dimbuene ZT \& Kyobutungi C (2019) Correlates of the double burden of malnutrition among women: an analysis of cross sectional survey data from sub-Saharan Africa. BMJ Open 9, e029545.

34. Onyango AW, Jean-Baptiste J, Samburu B et al. (2019) Regional overview on the double burden of malnutrition and examples of program and policy responses: African Region. Ann Nutr Metab 75, 127-130.

35. Ricci C, Asare H, Carboo J et al. (2019) Determinants of undernutrition prevalence in children aged 0-59 months in sub-Saharan Africa between 2000 and 2015. A report from the World Bank database. Public Health Nutr 22, $1597-1605$.

36. World Health Organization (2014) FAO/WHO Second International Conference on Nutrition (ICN2). https://www. who.int/news-room/events/detail/2014/11/19/default-calen dar/fao-who-second-international-conference-on-nutrition(icn2) (accessed March 2021).

37. Minnesota Population Center (2019) Integrated Public Use Microdata Series, International: Version 7.2 [dataset]. Minneapolis, MN IPUMS, 2019. https://international.ipums. org/international/citation.shtml (accessed July 2020).

38. GROUP WMGRS (2006) WHO Child Growth Standards based on length/height, weight and age. Acta Paediatr 450, 76-85.

39. WHO Consultation on Obesity 1999: Geneva S \& Organization WH (2000) Obesity: Preventing and Managing the Global Epidemic: Report of a WHO Consultation. Geneva: World Health Organization.

40. WHO (2011) Haemoglobin concentrations for the diagnosis of anaemia and assessment of severity. https://apps.who. int/iris/bitstream/handle/10665/85839/WHO_NMH_NHD_ MNM_11.1_eng.pdf?ua=1 (accessed March 2021).

41. Jones AD, Acharya Y \& Galway LP (2016) Urbanicity gradients are associated with the household- and individuallevel double burden of malnutrition in Sub-Saharan Africa. J Nutr 146, 1257-1267.

42. Alquaiz AM, Gad Mohamed A, Khoja TAM et al. (2013) Prevalence of anemia and associated factors in child bearing age women in Riyadh, Saudi Arabia. J Nutr Metab 2013, 636585.

43. Hwalla N, Al Dhaheri AS, Radwan H et al. (2017) The prevalence of micronutrient deficiencies and inadequacies in the middle east and approaches to interventions. Nutrients $\mathbf{9}$, 229.

44. Korenromp EL, Armstrong-Schellenberg JRM, Williams BG et al. (2004) Impact of malaria control on childhood anaemia in Africa - a quantitative review. Trop Med Int Heal 9, 1050-1065.

45. Grosse SD, Odame I, Atrash HK et al. (2011) Sickle cell disease in Africa: a neglected cause of early childhood mortality. Am J Prev Med 41, S398-S405.

46. Cappellini M \& Fiorelli G (2008) Glucose-6-phosphate dehydrogenase deficiency. Lancet 371, 64-74.

47. Sunuwar DR, Singh DR \& Pradhan PMS (2020) Prevalence and factors associated with double and triple burden of malnutrition among mothers and children in Nepal: evidence from 2016 Nepal demographic and health survey. BMC Public Health 20, 1-11.

48. Anik AI, Rahman MM, Rahman MM et al. (2019) Double burden of malnutrition at household level: a comparative study among Bangladesh, Nepal, Pakistan, and Myanmar. PLoS One 14, e0221274.

49. Ruel MT, Minot N \& Smith L (2005) Patterns and Determinants of Fruit and Vegetable Consumption in Sub-Saharan Africa: A Multicountry Comparison. Geneva: WHO.

50. Musaiger AO, Hassan AS \& Obeid O (2011) The paradox of nutrition-related diseases in the Arab countries: the need for action. Int J Environ Res Public Health 8, 3637-3671.

51. Wegmüller R, Bentil H, Wirth JP et al. (2020) Anemia, micronutrient deficiencies, malaria, hemoglobinopathies and malnutrition in young children and non-pregnant women in Ghana: findings from a national survey. PLoS One 15, 1-19. 
52. Petry N, Jallow B, Sawo Y et al. (2019) Micronutrient deficiencies, nutritional status and the determinants of anemia in children 0-59 months of age and non-pregnant women of reproductive age in The Gambia. Nutrients 11, 2275.

53. Wirth JP, Rohner F, Woodruff BA et al. (2016) Anemia, micronutrient deficiencies, and malaria in children and Women in Sierra Leone Prior to the Ebola Outbreak Findings of a Cross-Sectional Study. PLoS One 11, e0155031.

54. Mangemba NT \& San Sebastian M (2020) Societal risk factors for overweight and obesity in women in Zimbabwe: a crosssectional study. BMC Public Health 20, 103.

55. Jiwani SS, Gatica-Domínguez G, Crochemore-Silva I et al. (2020) Trends and inequalities in the nutritional status of adolescent girls and adult women in sub-Saharan Africa since 2000: a cross-sectional series study. BMJ Glob Heal 5, e002948.
56. World Health Organization (2016) Double-duty actions for nutrition: policy brief. https://www.who.int/ (accessed March 2021).

57. Romieu I, Dossus L, Barquera S et al. (2017) Energy balance and obesity: what are the main drivers? Cancer Causes Control 28, 247-258.

58. Darnton-Hill I, Nishida C \& James WPT (2004) A life course approach to diet, nutrition and the prevention of chronic diseases. Public Health Nutr 7, 101-121.

59. Department of Health SA (2017) Roadmap for Nutrition in South Africa. 1-50. https://extranet.who.int/nutrition/gina/sites/ default/filesstore/ZAF2013RoadmapforNutritioninSouthAfrica. pdf (accessed March 2021).

60. Government of Ghana (2016) National Nutrition Policy. https://www.unicef.org/ghana/media/1311/file/UN712528. pdf (accessed March 2021). 